\title{
Detection of emetic toxin (ces) gene and antimicrobial susceptibility of Bacillus cereus isolates from Iranian traditional dairy products
}

Mahdieh Heydarzadeh

Higher Education Institute of Rab-Rashid

Afshin Javadi ( $\square$ javadi@iaut.ac.ir)

Islamic Azad University Tabriz Branch

Mehdi Ghiami Rad

Islamic Azad University Ahar Branch

\section{Research}

Keywords: Bacillus cereus, Dairy products, Unpasteurized, ces gene

Posted Date: September 15th, 2020

DOI: https://doi.org/10.21203/rs.3.rs-61769/v1

License: (c) (i) This work is licensed under a Creative Commons Attribution 4.0 International License.

Read Full License 


\section{Abstract \\ Background}

Bacillus cereus is known as one of the major foodborne pathogens that often associated with the contamination of raw milk and dairy products. The aim of this study was to isolate the emetic toxinproducing Bacillus cereus (B. cereus) in unpasteurized traditional dairy products. Also, the antimicrobial resistance pattern was investigated in the isolates.

\section{Methods}

For this purpose, 150 samples of unpasteurized ice cream, cheese, doogh, curd and butter (prepared by traditional method) were randomly selected from the market from March 2019 to July 2020. Samples were evaluated for the presence of emetic toxin-producing $B$. cereus using culture and PCR method.

\section{Results}

Sixteen of $150(10.66 \%)$ samples were contaminated with $B$. cereus. This pathogen was isolated from one (3.33\%) sample of ice cream, $9(30 \%)$ of doogh, $6(20 \%)$ of curd in the mean contamination levels of $2.0 \pm 0.0$ and $4.4 \pm 0.6$, respectively. $B$. cereus was not isolated from cheese and butter samples. The contamination level of curd to this bacterium was significantly higher than other products $(p<0.05)$. PCR results showed that $14(78.5 \%)$ of 16 isolates contained the ces gene. The results of the antibiogram test showed that $B$. cereus isolates were resistant to penicillin, cefazolin and co-trimoxazole (trimethoprimsulfamethoxazole), semi-sensitive to vancomycin and erythromycin, and sensitive to gentamicin, ciprofloxacin and clindamycin. Also, $31.25 \%$ of isolates were resistant to six antibiotics simultaneously.

\section{Conclusion}

The findings of present study showed that traditional unpasteurized dairy products could provide a great potential for intoxication by antimicrobial-resistance and emetic toxin-producing strains of $B$. cereus.

\section{Background}

Bacillus cereus ( $B$. cereus) belonging to the Bacillaceae family is a gram-positive, spore-forming, facultative anaerobe, motile and rod-shaped bacterium with the size of $1 \times 3-4 \mu \mathrm{m}$ that is arranged in singly or in short chains (Evelyn \& Silva, 2015). It is an active hemolytic, catalase-positive, mannitolnegative and mesophilic bacterium, lacking rhizoid and containing phospholipase system (lecithinase). It has also the S-layer and beta-lactamase enzyme playing an important role in drug resistance (Dworkin et al. 2006). B. cereus strains are mostly saprophyte. They have a widespread in nature because of the 
resistance of their spores to various stresses and long survival in adverse environmental conditions (Messaoudi et al. 2010).

Bacillus cereus is known as one of the major foodborne pathogens that often contribute to the contamination of fast food and dairy products. It causes two types of food poisoning: diarrheal and emetic types (Le Lay et al. 2015). Diarrheal type of poisoning leads to abdominal pain and diarrhoea with the incubation period of $16-8$ hours. This disease causes by enterotoxins which are produced during the proliferation of $B$. cereus in the small intestine (Le Lay et al. 2015). Another type of disease is the emetic type with the incubation period of 1-5 hours that causes vomiting and nausea-like the food poisoning caused by Staphylococcus aureus (Kim et al. 2010; Schoeni, \& Lee Wong, 2005).

This type of intoxication is caused through the ingestion of emetic toxin named "cereulide". Cereulide can't be destroyed easily by heat treatment and it is stable at $126^{\circ} \mathrm{C}$ for 90 minutes. It is also resistant to acidic conditions of the stomach and proteolytic enzymes. Cereulide is encoded by ces gene. It binds to the 5-HT3 receptor and stimulates the vagal afferent nerve that causes nausea and vomiting. This effect leads to liver disorder. Recovery of histopathological changes and regeneration of hepatocytes occur after one week. Cereulide also causes cellular damages and inhibition of the natural killing activity of the human immune system cells (Dworkin et al. 2006; Ankolekar et al. 2009; Ehling-Schulz et al. 2005).

In addition to being a pathogenic microorganism, this bacterium is considered as an important cause of food spoilage due to its proteolytic, lipolytic and amylolytic activity. Because of some psychotropic types of this bacterium that are able to grow at $1-6{ }^{\circ} \mathrm{C}$, the food spoilage may also occur during storage at refrigerator temperatures. By the action of proteinase, lipase and phospholipases enzymes produced by B. cereus, some defects such as bad taste, the sweet and bitter clot can be observed in dairy products (Moradi-Khatoonabadi et al. 2014; Moradi-Khatoonabadi et al. 2015).

B. cereus usually contaminates the raw milk and it is considered as a major microbiological problem in the dairy industry. As a source of contamination in dairy products, its spores are resistant to heat treatments (Shaheen et al. 2010). In a study by Moradi et al. (2013), it was showed that most raw milk samples were contaminated with high levels of the spores of anaerobic bacteria especially $B$. cereus compared with national and international standards (Moradi-Khatoonabadi et al. 2014). In 2010, Williams and his colleagues conducted a study in Scotland and they reported that $28 \%$ of cheese samples made from raw milk were contaminated with $B$. cereus strains which were able to produce enterotoxin (Williams \& Withers, 2010). Cui et al. (2016) in a study in China showed that $9.8 \%$ of raw milk samples were contaminated with $B$. cereus and $1.1 \%$ of samples have ces gene. In a study by Messelhausser et al. (2010), from 809 samples of ice cream, 508 (62.7\%) samples were contaminated with B. cereus which 24 $(4.7 \%)$ of them contained cereulide producing gene (ces).

Since, $B$. cereus has important role in food poisoning and spoilage in dairy products and these products are the most consumed food in the human diet, the aim of this study was to determine the prevalence of this bacterium in traditional unpasteurized dairy products, compare the contamination level with standard limit and evaluate the frequency of ces gene and antimicrobial susceptibility pattern of isolates. 


\section{Methods}

In the present study, 150 samples of unpasteurized dairy products including cheese, butter, curd, doogh (a savoury yogurt-based beverage in Iran) and ice cream (30 samples from each product) were randomly purchased from the markets in Tabriz city (Iran) between March 2018 to July 2019. They were transferred aseptically to the laboratory of food hygiene for detection and enumeration of $B$. cereus using culture method and PCR technique.

Dilutions of $10^{-1}, 10^{-2}$ and $10^{-3}$ of samples were prepared and cultured in MYP agar (Mannitol egg-yolk polymyxin phenol red agar) (Merck, Germany) according to the Iranian national standard. Large and pink colonies with a halo detected and enumerated as $B$. cereus. Isolates were also confirmed by hemolysis test and Gram staining (ISO 7932, 2004).

According to the Kirby-Bauer method, the antibiotic susceptibility pattern of isolates was studied using the disks of antibiotics which are currently used in the area. The sensitivity level and drug resistance were determined according to the CLSI standard (CLSI, 2016).

PCR test was performed to detect the ces gene in the isolates. For this purpose, DNA extraction was done by boiling method. Nanodrop spectrophotometer was used to evaluate the concentration and purity of extracted DNA samples. Amplification of $154 \mathrm{bp}$ product of ces gene was performed using the designed primers (Table 1) (Zhihong et al. 2014). The used components for PCR and their concentrations are shown in Table 2. PCR program included an initial denaturation in $94^{\circ} \mathrm{C}$ for 3 minutes, followed by 35 cycles of denaturation at $94{ }^{\circ} \mathrm{C}$ for 35 seconds, annealing at $55^{\circ} \mathrm{C}$ for 35 seconds, extension at $72{ }^{\circ} \mathrm{C}$ for 10 seconds and 1 cycle of final extension at $72{ }^{\circ} \mathrm{C}$ for 5 minutes.

Table 1

The used primers in PCR test (Zhihong et al.)

\begin{tabular}{|lll|}
\hline Primer & Sequence & Amplicon length \\
\cline { 1 - 2 } cesB-F: & $5^{\prime}$ - ACCCATCTTGCGTCATT - 3' & 154 bp \\
\cline { 1 - 2 } cesB-R: & $5^{\prime}$ - CAGCCAAGTGAAGAATACC - 3' & \\
\cline { 1 - 2 } & &
\end{tabular}


Table 2

Components of Polymerase chain reaction

\begin{tabular}{|lll|}
\hline Component & Volume for each test & Total volume for 16 tests \\
\hline Master mix & $12.5 \mu \mathrm{l}$ & $200 \mu 1$ \\
\hline Primer forward & $\mathrm{L} \mu \mathrm{l}$ & $16 \mu 1$ \\
\hline Primer reverse & $\mathrm{L} \mu \mathrm{l}$ & $16 \mu 1$ \\
\hline DNA & $\mathrm{L} \mu \mathrm{l}$ & $16 \mu 1$ \\
\hline $\mathrm{dH}_{2} \mathrm{O}$ & $9.5 \mu \mathrm{l}$ & $152 \mu 1$ \\
\hline Total & $25 \mu \mathrm{l}$ & $400 \mu 1$ \\
\hline
\end{tabular}

In order to separate the amplified segments; the $1 \%$ agarose gel was prepared and DNA safe stain was added to it. The ladder was loaded into the first well. The next wells were loaded with samples (mixed with loading buffer). A positive sample of $B$. cereus PTCC: 1015 was used as a positive control. Then, the lid of the electrophoresis tank was closed. After setting the electric voltage on $100 \mathrm{~V}$, the electrophoresis of PCR products was performed for 45 minutes. Afterward, the gel was removed slowly and results were visualized by ultraviolet radiation.

Results were analyzed by SPSS software (version 18) and presented using the indicators of the central tendency and dispersion. For comparison of the contamination level of dairy products with national standard limit $\left(<1 \times 10^{2}\right)$ and the contamination level between products, one sample T-test and chi-square test at $95 \%$ confidence level and $a=5 \%$ were used, respectively.

\section{Results}

In the present study, 150 samples of traditional dairy products were evaluated of which 16 samples were contaminated with $B$. cereus. The contamination level of each unpasteurized dairy product is shown in Table 3. 
Table 3

The contamination level of dairy products to Bacillus cereus and presence of ces gene

\begin{tabular}{|lllll|}
\hline Sample & $\begin{array}{l}\text { Total } \\
\text { number }\end{array}$ & $\begin{array}{l}\text { Number of } \\
\text { positive samples }\end{array}$ & $\begin{array}{l}\text { Average microbial load } \\
\left(\text { Log }_{10} \text { CFU/gr or ml) }\right.\end{array}$ & $\begin{array}{l}\text { Number of Ces gene } \\
\text { positive samples }\end{array}$ \\
\hline Curd & 30 & $6(\% 20)$ & $0.6 \pm 4.4$ & $6(\% 100)$ \\
\hline Doogh & 30 & $9(\% 30)$ & $0.6 \pm 1.8$ & $8(\% 88.88)$ \\
\hline $\begin{array}{l}\text { Ice- } \\
\text { cream }\end{array}$ & 30 & $1(\% 3.33)$ & $0 \pm 2$ & ND* \\
\hline Cheese & 30 & ND & 0 & ND \\
\hline butterB & 30 & ND & 0 & ND \\
\hline *ND: not detected & & & \\
\hline
\end{tabular}

The results of the chi-square test showed a significant difference between dairy products about the contamination of $B$. cereus. The highest contamination level was detected in curd and the lowest level of contamination was found in cheese and butter $(p<0.001)$. The results of t-test showed that the contamination level of curd has a significant difference with the national standard limit of $\operatorname{Iran}\left(1 \times 10^{2}\right)$ $(p<0.05)$ (Fig. 1).

The results of the antibiogram test (Table 4) showed that most of the isolates were resistant against penicillin, cefazolin and co-trimoxazole, sensitive against gentamicin, ciprofloxacin and clindamycin and semi-sensitive to vancomycin and erythromycin, respectively. 
Table 4

Antibiotic susceptibility test according to the number and percentage of resistant, semi-sensitive and sensitive isolates

\begin{tabular}{|lllllll|}
\hline Antibiotics & $\mathbf{R}$ & I & & S & \\
\cline { 2 - 7 } & $\begin{array}{l}\text { No. of } \\
\text { samples }\end{array}$ & Percent & $\begin{array}{l}\text { No. of } \\
\text { samples }\end{array}$ & Percent & $\begin{array}{l}\text { No. of } \\
\text { samples }\end{array}$ & Percent \\
\hline Penicillin & 16 & $\% 100$ & 0 & $\% 0$ & 0 & $\% 0$ \\
\hline Cefazolin & 16 & $\% 100$ & 0 & $\% 0$ & 0 & $\% 0$ \\
\hline Vancomycin & 8 & $\% 50$ & 3 & $\% 18.75$ & 5 & $\%$ \\
\hline Clindamycin & 5 & $\%$ & 3 & $\% 18.75$ & 8 & 31.25 \\
\hline Erythromycin & 7 & 31.25 & & $\% 18.75$ & 6 & $\% 50$ \\
\hline Ciprofloxacin & 0 & $\% 43.75$ & 3 & $\% 50$ & 8 & $\% 57.5$ \\
\hline Gentamycin & 2 & $\% 0$ & 8 & $\% 0$ & 14 & $\% 87.5$ \\
\hline $\begin{array}{l}\text { Co- } \\
\text { trimoxazole }\end{array}$ & 10 & $\% 12.5$ & 0 & $\% 18.75$ & 3 & $\% 18.75$ \\
\hline
\end{tabular}

The results of the PCR test showed that 14 of 16 isolates were contained the ces gene. As shown in Fig. 2, the ces gene was not detected in samples of No. 1 and No. 16 but the other samples formed the related band in $154 \mathrm{bp}$ segment. All isolates from the curd and doogh except for one contained ces gene. The only isolate from ice cream lacked this gene.

\section{Discussion}

Milk and dairy products are the most consumed and important resources in the daily diet of human. They also provide a considerable part of the public's needs for nutrients because of having a variety of vitamins and minerals including calcium.

The attitude of consumers about the side effects of additives in the dairy industry increases their tendency toward the consumption of milk, traditional dairy products and products made from unprocessed or semi-processed milk. Because of the possible presence of human pathogenic microorganisms, consumption of products produced from raw milk can be harmful (Verraes et al. 2015).

In this study, from a total 150 samples of dairy products, 16 samples $(10.66 \%)$ were contaminated to $B$. cereus. These results are somewhat in accordance with the findings of Reyes et al. (2013) who reported that from 260 samples of milk and dairy products, $24.23 \%$ were contaminated to this bacterium (Reis et al. 2013). 
In this study, just one (3.33\%) of 30 samples of tested ice cream was detected as contaminated with $B$. cereus. Messelhausser et al. (2010) were carried out a study on 809 ice cream samples and reported that $62.7 \%$ of samples were contaminated with $B$. cereus (16). However, among the performed studies about the contamination of ice cream with B. cereus in Iran, Pour-Mohammadi et al. (2002) and Shakerian et al. (2005) isolated this bacterium in $1.5 \%$ and $12 \%$ of samples, respectively.

So, the present study was not inconsistent with Messelhausser et al. but in accordance with the studies was performed in Iran. The difference between the results of present research with the findings of Messelhausser et al. may be related to different hygienic conditions in various stages of production, packaging and distribution in different countries.

From 30 traditional cheeses that were evaluated in this study, no positive results were found in the samples. However, according to the findings of Williams et al. (2010) in Scotland, $28 \%$ of cheese samples produced from raw milk was contaminated with $B$. cereus. Since $B$. cereus can't tolerate the salt concentration more than $7.5 \%$, this contradiction may be due to high salinity in Lighvan cheese $(11 \%)$, which is known as a type of salty high-fat cheese.

In the present study, $6(20 \%)$ of 30 curd samples were contaminated with B. cereus. Most of the production process of traditional curd is performed manually using traditional equipments. It also airdried in sunlight. So, all of these processes can increase the risk of product contamination by spoilage microorganisms especially $B$. cereus which can easily contaminate the product by dust.

From 30 samples of Doogh evaluated in this study, 10 (30\%) samples were contaminated with B. cereus. However, Keshtkar et al. (2012) evaluated the samples of pasteurized dairy products that were marketed in the cities of Tehran, Isfahan, Shiraz, Semnan and Shahr-e Kord and they found that $16.66 \%$ of doogh samples contaminated with $B$. cereus. The lack of inconsistency between findings can be explained by pasteurized dairy products evaluated in the study of Keshtkar et al. and unpasteurized samples with manual and traditional production in the present study. So, production processes and the use of unpasteurized milk can play a role in the contamination level of products.

In the present study, from 30 samples of traditional butter, there was no contamination with this bacterium. In a study by Faramarzi et al. (2011) about the contamination of traditional butter with pathogenic microbes, no positive sample was detected as contaminated with $B$. cereus. This may be due to the weight of $B$. cereus spores which can be deposited in the solution made from the butter.

The findings of this study about the presence of ces gene in the isolates showed that 14 (87.5\%) of 16 samples contained the ces gene. However, Messelhausser et al. (2010) reported that 24 (4.7\%) of 508 isolates from ice cream samples have the cereulide producing gene (ces). In another study by Samapundo et al. (2011) on cooked pasta, mince and lasagna in Belgium, none of 81 isolates of $B$. cereus expressed ces gene for production of emetic toxin. 
Cui et al. (2016) reported that from $9.8 \%$ of $B$. cereus isolates in raw milk samples, $1.1 \%$ contained ces gene. Since there is no similar study about the presence of ces gene in curd and doogh, the possible reason for the high content of this gene in these products can also be associated with sanitary conditions in their production.

The study of antibiotic susceptibility pattern of isolates showed that most of them were resistant against penicillin, cefazolin and co-trimoxazole. But they were sensitive against gentamicin, ciprofloxacin and clindamycin and semi-sensitive against vancomycin and erythromycin. The findings of Jalalpour \& Abusaeedi (2009) were somewhat similar to results of present study. They found that all strains were resistant against the selected antibiotic against Bacillus infections, which was penicillin. However, they have a significant sensitivity against vancomycin, tetracycline and erythromycin. It should be noted that the antibiotic selective stress in each area could be the reason for similarities or differences in antibiotic pattern. In addition, excessive use of antibiotics may lead to resistant strains in the environment.

\section{Conclusion}

The findings of this research indicate that the contamination of unpasteurized dairy products with $B$. cereus. Regarding high antibiotic resistance and detection of ces gene, there is a potential of intoxication by these products, especially by curd and doogh. So, the preparation and production of these products should carry out carefully. In order to reduce the contamination level to this bacterium which is highly resistant to environmental conditions, it is better to replace unpasteurized dairy products with pasteurized ones.

\section{Declarations}

\section{Availability of data and materials}

All quantitative data generated or analysed during this study are included in this article.

\section{Ethics approval and consent to participate}

Not applicable.

\section{Consent for publication}

Not applicable.

\section{Competing Interests}

The authors declare that they have no conflict of interest. 


\section{Funding}

This work was performed only by our personal funding.

\section{Authors' contributions}

Mahdieh Heydarzadeh: Data curation, funding, investigation, project administration; Afshin Javadi: Conceptualization, design of methodology, supervision for the research activities, writing of the original draft, writing and editing of the manuscript; Mehdi Ghiami Rad: Conceptualization, design of methodology, analysis and verification of data, editing of the manuscript. All authors have read and approved the final manuscript.

\section{Acknowledgments}

This article is provided from the thesis of Mahdieh Heydarzadeh entitled "Isolation \& enumeration of $B$. cereus in marketed unpasteurized dairy products and detection of "ces" gene in master degree in the Higher Education Institute of Rab-Rashid, Tabriz, Iran. Authors are grateful from all individuals and institutes including food hygiene laboratory and biotechnology research centre in the faculty of veterinary medicine, Azad University, Tabriz branch for their help in performing of this research.

\section{References}

1. Ankolekar C, Rahmati T, Labbé RG. Detection of toxigenic Bacillus cereus and Bacillus thuringiensis spores in US rice. International journal of food microbiology. 2009; 128: 460-466.

2. Cui Y, Liu X, Dietrich R, Märtlbauer E, Cao J, Ding S, Zhu K. Characterization of Bacillus cereus isolates from local dairy farms in China. FEMS microbiology letters. 2016;363:fnw096.

3. CLSI. (2016) Performance Standards for Antimicrobial Susceptibility Testing (M100S), 26th edition. URL: http://ljzx.cqrmhospital.com/upfiles/201601/20160112155335884.pdf. Accessed 02/13/2017.

4. Dworkin M, Falkow S, Rosenberg E, Schleifer KH, Stackebrandt E. The Prokaryotes: A handbook on the biology of bacteria, 2006, New York, Springer.

5. Ehling-Schulz M, Vukov N, Schulz A, Shaheen R, Andersson M, Märtlbauer E, Scherer S. Identification and partial characterization of the nonribosomal peptide synthetase gene responsible for cereulide production in emetic Bacillus cereus. Applied Environmental Microbiology. 2005;71:105-13.

6. Evelyn E, Silva FV. Thermosonication versus thermal processing of skim milk and beef slurry: modeling the inactivation kinetics of psychrotrophic Bacillus cereus spores. Food Res Int. 2015;67:67-74.

7. Faramarzi T, Jonidi Jafari A, Dehghani S, Mirzabeygi M, Naseh M, Rahbar Arasteh H. A survey on Bacterial Contamination of Food Supply in the West of Tehran. Journal of Fasa University of Medical Sciences. 2012;2:11-8. 
8. Jalalpoor S, Abousaidi H. Survey Role and Important of Surfaces Structure and $\beta$-lactamase of Bacillus cereus in Drug Resistant. Journal of Microbial World. 2009;2:169-76.

9. ISO 7932. Microbiology of food and animal feeding stuffs - Horizontal method for the enumeration of presumptive Bacillus cereus colony - count technique at $30^{\circ} \mathrm{C}$. 2004 , URL: http://www.iso.org/iso/catalogue_detail.htm?csnumber=38219. Accessed 02/13/2017..

10. Keshtkar M. Prevalence and molecular characterization of Bacillus cereus isolated from milk and dairy products, Ph. D. thesis, Faculty of Agriculture, Islamic Azad University of Damghan. 2012.

11. Kim JB, Kim JM, Park YB, Han JA, Lee SH, Kwak HS, Hwang IG, Yoon MH, Lee JB, Oh DH. Evaluation of various PCR assays for the detection of emetic toxin producing Bacillus cereus. Journal of microbiology biotechnology. 2010;20:1107-13.

12. Le Lay J, Bahloul H, Sérino S, Jobin M, Schmitt P. Reducing activity, glucose metabolism and acid tolerance response of Bacillus cereus grown at various $\mathrm{pH}$ and oxydo-reduction potential levels. Food microbiology. 2015;46:314-21.

13. Messelhäusser U, Kämpf P, Fricker M, Ehling-Schulz M, Zucker R, Wagner B, Busch U. and Höller C. Prevalence of emetic Bacillus cereus in different ice creams in Bavaria. J Food Prot. 2010;73:395-9.

14. Messaoudi K, Clavel T, Schmitt P, Duport C. Fnr mediates carbohydrate-dependent regulation of catabolic and enterotoxin genes in Bacillus cereus F4430/73. Research in microbiology. 2010;161:30-9.

15. Pourmahmoodi A, Mohammadi J, Mirzai A, Momeni NM, Afshar R. Epidemiological study of traditional Ice cream in Yasuj. Armaghan Danesh. 2003;8:59-65.

16. Moradi-Khatoonabadi Z, Ezzatpanah H, Maghsoudlou Y, Khomeiri M, Aminafshar M. Bacillus Cereus Contamination of UF-Feta Cheese during Ripening and Shelf Life. Journal of Food Safety. 2015;35:41-9.

17. Moradi-Khatoonabadi Z, Maghsoudlou Y, Ezzatpanah H, Khomeiri M, Aminafshar M. Occurrence of Bacillus cereus in raw milk receiving from UF-Feta Cheese Plants. Iranian Journal of Health Environment. 2014;6:545-56.

18. Reis AL, Montanhini M, Bittencourt JV, Destro MT, Bersot LS. Gene detection and toxin production evaluation of hemolysin $\mathrm{BL}$ of Bacillus cereus isolated from milk and dairy products marketed in Brazil. Brazilian Journal of Microbiology. 2013;44:1195-8.

19. Samapundo S, Heyndrickx M, Xhaferi R, Devlieghere F. Incidence, diversity and toxin gene characteristics of Bacillus cereus group strains isolated from food products marketed in Belgium. International journal of food microbiology. 2011;150:34-41.

20. Schoeni JL, Lee Wong AC. Bacillus cereus food poisoning and its toxins. Journal of food protection. 2005;68:636-48.

21. Shaheen R, Svensson B, Andersson MA, Christiansson A, Salkinoja-Salonen M. Persistence strategies of Bacillus cereus spores isolated from dairy silo tanks. Food microbiology. 2010;27:347-55.

22. Shakerian A, Karim G, Tajbakhsh E, Shafei M. Investigating the Microbial Contamination of Traditional Ice Creams in Shahr-e-kord. Iranian Journal of Food Science Technology. 2005;2:20-7. 
23. Shekarforoush SS, Razavi RS, Karim G, Kiaie SM, Rokni N, Abbasvali M. Study on the overview on food borne bacteria in foodstuffs with animal origin in Iran, Part one: milk and dairy products. Journal of Food Hygiene. 2012;2:1-30.

24. Soleimaninanadegani M. Evaluation of critical level in Bacillus Cereus growth curve in milk products with different conditions based on experimental data and ComBase Predictive Models. Webmed Central. 2013;4:2046-1690.

25. Verraes C, Vlaemynck G, Van Weyenberg S, De Zutter L, Daube G, Sindic M, Uyttendaele M, Herman L. A review of the microbiological hazards of dairy products made from raw milk. International Dairy Journal. 2015;50:32-44.

26. Williams AG, Withers SE. Microbiological characterisation of artisanal farmhouse cheeses manufactured in Scotland. International journal of dairy technology. 2010;63:356-69.

27. Zhang Z, Wang L, Xu H, Aguilar ZP, Liu C, Gan B, Xiong Y, Lai W, Xu F, Wei H. Detection of non-emetic and emetic Bacillus cereus by propidium monoazide multiplex PCR (PMA-mPCR) with internal amplification control. Food Control. 2014;35:401-6.

\section{Figures}

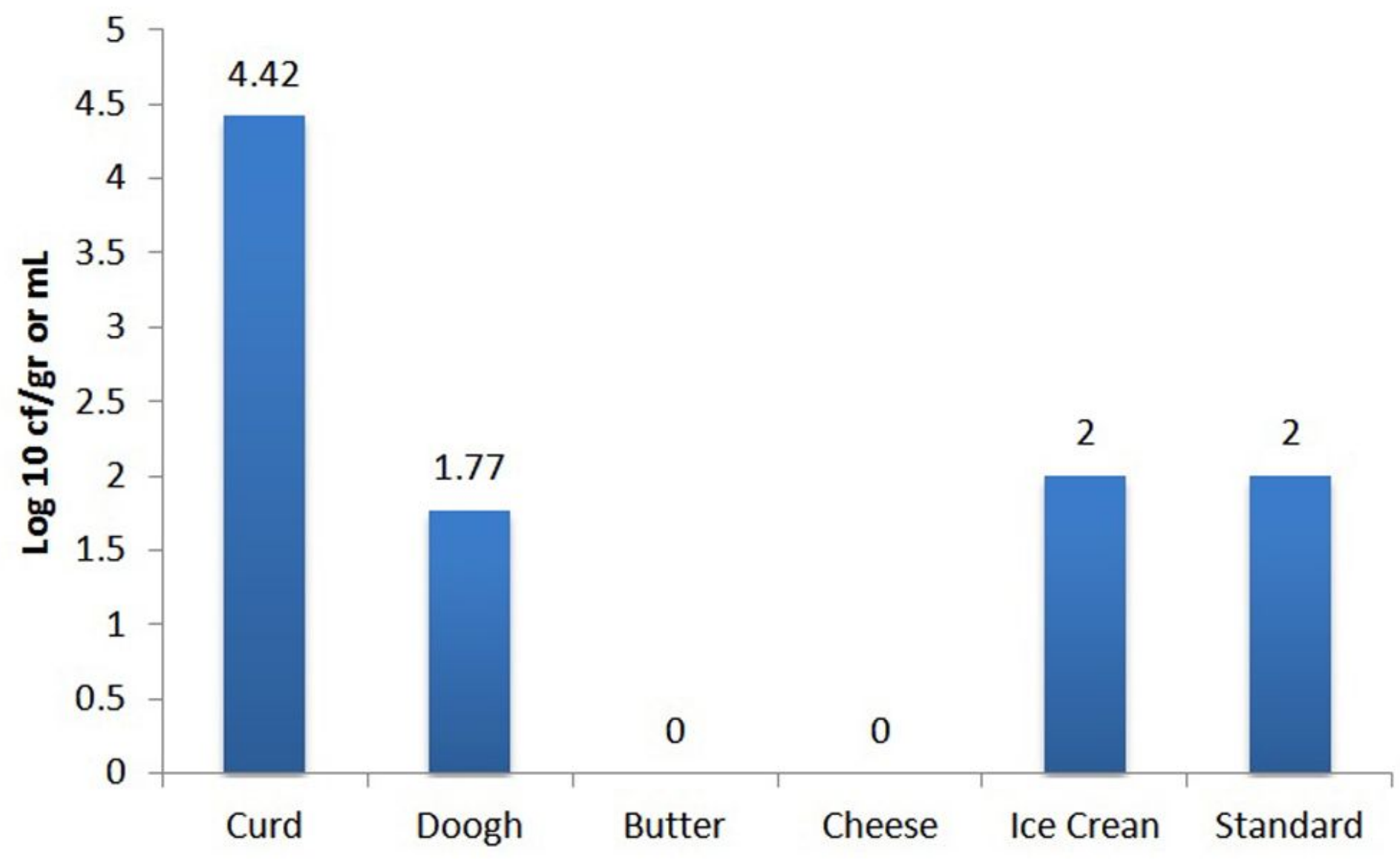

Figure 1 
The results of T- test, comparison of the contamination level of dairy products with national standard level $(1 \times 102)$
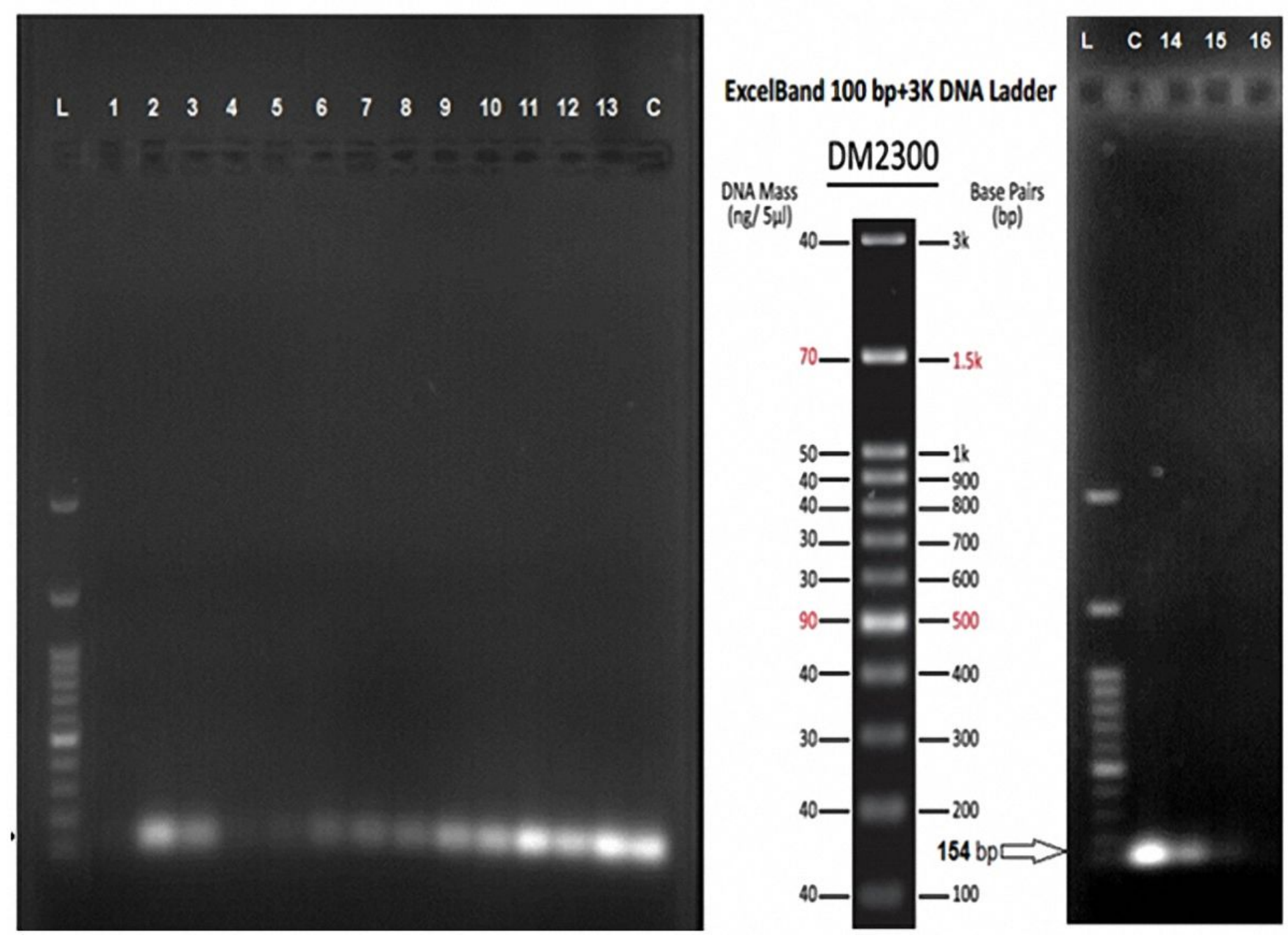

Figure 2

Electrophoresis of Bacillus cereus isolated from the samples of dairy products, No. 1-16: Isolated samples, L: DNA Ladder, C: positive control 